\title{
IMAGES OF BEHAVIOR ANALYSIS: THE SHAPING GAME AND THE BEHAVIORAL STREAM
}

\author{
Michael Keenan \\ University of Ulster, Coleraine \\ Karola Dillenburger \\ The Queen's University of Belfast
}

\begin{abstract}
This paper points to the lack of scientific images, including moving images, for promoting behavior analysis. Examples of what could be done to rectify this situation are contained in two teaching gambits that address practical and philosophical issues in the analysis of behavior. The first gambit is an elaboration of the shaping game that highlights issues associated with discriminative control and the role of private events in the analysis of behavior. The second gambit uses specially designed graphics, both 2-D and 3-D, to show how an understanding of the behavioral stream underpins every aspect of the analysis of behavior.
\end{abstract}

Key words: behavioral stream, classroom exercise, epistemology, images, mentalism, misrepresentation, private events, shaping, stimulus control, teaching.

A damaging effect that arises from misrepresentation of behavior analysis in introductory textbooks in psychology is that students are encouraged to view behavior analysis as of historical interest only, or as useful only for people with learning difficulties (cf. Catania, 1991; Lee, 1989; Lonigan, 1990; Morris, 1985, 1990, 1992; Wyatt, 1990). Aligned with this are the problems created by teachers not trained in behavior analysis who teach behavior analysis as a segment within a traditional psychology course. As products of the same educational system over which they now have jurisdiction these teachers may not, and cannot be expected to, present behavior analysis accurately.

Efforts to counter misrepresentation are gaining momentum, as evidenced, for example, by the creation of a special interest group in the Association for Behavior Analysis called BALANCE that is devoted to exposing misrepresentation in the media. However, although it is important to counter the effects of faulty learning on the part of those who write introductory textbooks in psychology, it may prove to be valuable only as a damage limitation exercise. Indeed it would not be surprising if authors of textbooks that misrepresent behavior analysis were not interested in being (re)educated, for such is the nature of prejudice.

The simple argument we make in this paper is that more attention needs to be focused on developing classroom exercises that portray the sophistication of many of the facets of behavior analysis (see also Keenan, 1997a, 1997b). If students are

AUTHORS' NOTE: Reprints may be obtained from Mickey Keenan, School of Psychology and Communication, University of Ulster, at Coleraine, Coleraine, County L'Derry, N. Ireland, BT52 1SA. Email: m.keenan@ulst.ac.uk. 


\section{KEENAN \& DILLENBURGER}

lucky enough, their first encounter with the practices of behavior analysis can take place in the animal laboratory. There, students learn about the effects of contingencies by changing the behavior of a rat or a pigeon. This experience makes for an invaluable foundation for addressing epistemological issues that arise in the study of behavior generally. But how should teachers teach if they are in departments that do not have animal facilities? The same question applies to teachers who do not have access to clinical populations. What if the teacher is in a Social Work department where students have been taught by other staff members to despise the very notion of behavior analysis?

As far as we are aware there is no "laboratory manual" that can be used by teachers in a variety of educational settings as a resource for guidance on how to sell the ideas of behavior analysis. The word "sell" is emphasized deliberately because the teaching context determines the way in which material is to be presented, if the teacher is to be successful, that is, in making students interested in what behavior analysis has to offer. Under these circumstances the only option is to turn to the many introductory textbooks written by behavior analysts (e.g., Catania, 1997; Leslie, 1996; Miltenberger, 1997).

All textbooks in behavior analysis rely on data produced from academic journals to facilitate the "PR" exercise that is part and parcel of teaching behavior analysis in an undergraduate degree course in psychology. Students are presented with the success stories of procedures that produced lasting changes in the behavior of individuals. And that, one would think, should be enough to make most people interested in what can be achieved by our discipline. But it isn't! Indeed the relative failure of the discipline of behavior analysis to promote itself has given rise to much debate about whether or not it should even be taught within psychology departments (Fraley, 1997; Grote, 1997; Johnston, 1997; Rakos, 1997; Wulfert, 1997). Commenting on Fraley's (1997) suggestion that behavior analysis is best served by becoming more independent from psychology, Johnston (1997) said:

Those of us who have been fighting the good fight for more than 25 years can appreciate the considerable impact that behavioral philosophy and methods have had within psychology, while remaining frustrated by the distance yet to go. For the next 25 years, there seems little choice for most academic behavior analysts but to persevere within psychology's dysfunctional family. There is good reason to be hopeful that we will yet realize our desires for influencing the way psychology defines and approaches its subject matter. (pp. 100-101)

How things pan out eventually is anybody's guess. No doubt in years to come some historical review will be able to trace the effects of contingencies put in place by behavior analysts to help realize their desires. The purpose of this paper is to suggest one particular avenue that has not been explored to its full extent.

Our starting point is to propose that there are limitations in what a teacher can achieve by relying solely on the printed word (see also Keenan, 1998; Keenan \& Dillenburger, 2000). This is self-evident on one level and that is why practical classes (if you can find guidelines for them) are incorporated into the learning 
experience for students. However, a major problem exists also with various other discriminative stimuli contained within an academic paper. The discriminative stimuli we refer to consist simply of "dots on a graph." These stimuli are presented to students with the assumption that they can function as stimuli that will excite students about what can be achieved with behavior analysis. In terms of acquiring discriminative control over the "Wow!" experience, dots printed on a twodimensional space can never take the place of video material that shows the behavior being studied. These dots are the shorthand used by professional scientists already interested in behavior analysis. When it is considered that they are virtually the only visual discriminative stimuli that are employed by most teachers, it is surprising that their usefulness in controlling student interest has not been assessed with the usual thoroughness that is the hallmark of behavior analysis.

To emphasize this point consider the following scenario. Picture a group of students who are invited to the preview of a new movie. Seated in the auditorium they are given a brief overview of the movie by the director. The lights dim and the curtains open to the sound of rapturous applause. In the subsequent silence the students are treated to pages of text projected onto the screen. Punctuated throughout the text are two-dimensional black and white Tables and Figures that summarize aspects of the plot.

Given the technological advancements that exist within the social context for these students, you wouldn't need a research grant to help you make an educated guess about the success of the movie. But this is precisely what we do in our teaching! Having designed our discriminative stimuli (i.e., two-dimensional black and white Tables and Figures) we then actively design educational contingencies to ensure that students remain on task when it comes to digesting printed material.

There was a time when the printing press revolutionized the way in which people communicated. That time has long since passed but its heritage has left us short sighted in terms of the variety of methods we employ to communicate our ideas. Because there are limitations in the way we can enhance the effectiveness of the printed word, a teacher might decide to turn to practical exercises to supplement the learning/PR experience in class. However, most introductory textbooks in behavior analysis do not contain guidelines for specific exercises that can be used in the classroom. Again this is a curious state of affairs for a discipline that recognizes the importance of controlling learning environments. We have millions of pages in journals outlining in detail the precise steps to be taken when conducting a particular study. Very few pages exist, though, that outline procedures that can be adapted to the social context of the teaching environment.

The two exercises described next were designed to address this vacuum. They focus on some basic conceptual issues that are distinguishing features of behavior analysis. The first exercise, The Shaping Game, provides some practical skills and is an elaboration of training procedures used by animal trainers. The aim of the second exercise, The Behavioral Stream, is to elaborate on epistemological issues touched on in the shaping game, using specially prepared graphics as a visual context for controlling the evolution of a dialogue between teacher and student. 


\section{KEENAN \& DiLLENBURGER}

\section{The Shaping Game}

The shaping game is basically a variation of the children's party game widely known as "hot and cold." In this game, one player is blindfolded, an object, such as a prize or sweets, is then hidden in the room, and the audience guides the players' searching by shouting "hot" as they gradually move closer to the hidden object and "cold" if they move further away from it. Pryor (1985, pp. 51-82) describes a similar exercise that she uses in her courses for animal trainers (see also, Morgan, 1974). In brief, she sends one volunteer out of the room, while the other students decide on a target behavior that this volunteer is to perform. When the student returns to the room the "trainer" shapes the desired behavior using a "clicker"; when the target behavior is performed the whole class claps.

This game is usually well received by students. While it is advisable to start with simple target behaviors such as "writing something/anything on the blackboard," the choice of target behaviors can become more and more adventurous. It can be fun, for example, to observe someone being shaped to perform more difficult behaviors such as "scratching their right ear with their left hand" or "hopping on one leg while patting oneself on the head." Bailey and Bailey (1993) provide invaluable guidelines for even more sophisticated target behaviors including shaping the behavior of a group of people. In this version of the shaping game we have expanded it to cover the following objectives:

1. Teach the basic principles involved in shaping.

2. Teach about the power of contingencies of reinforcement.

3. Demonstrate the operation of stimulus control.

4. Demonstrate the value and difficulty of continuously monitoring the behavior of a single organism.

5. Demonstrate how questionnaires produce an incomplete account of behavior.

Below we outline how these objectives can be achieved in a number of variations of the original shaping game:

\section{Teach basic principles involved in shaping.}

\section{Teach about the power of contingencies of reinforcement.}

Initially students are given a free reign in deciding which behaviors to shape. They should be encouraged to enjoy the exercise by shaping the behavior of about four or five of their peers. Because the people being shaped will almost certainly engage in "unwanted" behaviors, the timing and frequency of reinforcer delivery, and mistakes therein, become the focus of discussion.

\section{Demonstrate the operation of stimulus control.}

In order to demonstrate the principle of stimulus control, the shaping game is played using an agreed upon, well-defined target behavior such as "walking over to the blackboard, lifting a piece of chalk from the board, carrying the chalk over 
to a desk, and placing the chalk on top of a duster that is lying on the desk." This time, however, a number of stimuli that function as discriminative stimuli in other (perhaps similar) contexts should be strategically placed in the path of the person who is to be shaped. For example, a chair can be placed directly underneath the place where the chalk is to be picked up; a cup or other container can be placed directly in front of the duster. Prepare the class for a subsequent discussion on the notions of prediction and control by predicting for them what the person being shaped will do in the presence of these discriminative stimuli. Tell them, for example, that this person is likely to sit on the chair and that they probably will place the chalk in the container. When the volunteer returns to the room and the shaping game begins the class will be on tender hooks as they wait to see the behaviors you have predicted. Since the voluntary behaviors of a number of subjects will be similar, there is ample opportunity to develop a class discussion around the meaning of the terms "stimulus control" and "voluntary control of behavior" as well as the scientific concepts of prediction and control.

\section{Demonstrate the value and difficulty of continuously monitoring the behavior of a single organism.}

The basic shaping game as described above should be played while some students separately monitor the behavior that occurs. Give each of these observers a clear plastic sheet for an overhead projector and two colored pens. This clear sheet should picture the rough layout of the room. Each observer is instructed simply to draw a continuous line on the sheet to indicate the location of the subject in the room at any time. Tell them to mark each reinforcer delivery with the other colored pen. This monitoring procedure is best used together with the following variation of the game.

\section{Demonstrate how questionnaires produce an incomplete account of behavior.}

Ask half of the class to leave the room before playing the shaping game. After playing the game bring them back in. The half of the class that was not present during the exercise is instructed to role-play a researcher who deals only with questionnaires. They are free to ask the subject any questions they wish. For example, they may ask, "What did you do?" In this case they may get an answer such as "I went over to the blackboard, picked up a piece of chalk, walked over to the desk and put it in the cup." The class members who observed the shaping exercise see immediately the extent to which information has been lost.

Once the above "interview" is finished to everyone's satisfaction, the sheets on which the behavior was recorded earlier are placed on the overhead projector to show some details of what really happened. That is, the data collected by the continuous monitoring procedure are presented. The ensuing discussion can then revolve around the following themes:

1. the complexity of the behavioral changes that took place;

2. any regularities in patterning across subjects; 


\section{KEENAN \& DILLENBURGER}

3. the individual differences in patterning and number of reinforcers that would have been lost by group statistics;

4. the function of discriminative stimuli;

5. the importance of this information to explain what happened to those who didn't see it; what was it that they missed out on when they had to rely on data collected by questionnaires?;

6. the need for a systematic method for recording behavior. When students see the differences in the records kept by each of the observers they are often surprised. It is often assumed, for example, that it "should be relatively easy to record a simple behavior" that occurs during the shaping game. This aspect of the gambit serves as a useful introduction to further classes designed to cover issues concerned with recording behavior.

\section{Example of resulting class discussion}

The objectives of this gambit are to show students how the practical skill involved in shaping behavior has important implications over and above the demonstration that contingencies of reinforcement control behavior. As an example of what can be expected in a classroom discussion during the exercise, we will now outline some points raised by students who took part in this exercise during their second year of undergraduate studies. You might use these points to spark a classroom discussion, or you might use them as guidelines as you try to provoke your class into coming to similar conclusions.

A female student had been shaped to pick up a plastic cup, walk over to a desk, turn the cup upside down, and place it on top of a bottle that was standing on the desk. In the discussion afterwards, she insisted that it was her decision to place the cup on top of the bottle and that this was done before she received any reinforcement for doing so. This is a very common comment and her interpretation of events was an indication of her doubt in the ability of behavior analysis to account for the behavior she had just performed. From a teaching point of view, this comment is precisely the behavior the teacher should aim to produce. Its value lies in the fact that discussions on this topic in a textbook do not involve the behavior of the person being taught. Rather, discussions on agency or mentalism are usually centered around the behavior of someone else.

Under these circumstances the challenge for the teacher is two-fold. Instructional contingencies need to be devised to persuade the student of the efficacy of dismissing mentalism while at the same time ensuring that the student does not confuse these arguments with the suggestion that people are to be treated as "black boxes." To deal with her comments constructively, then, the student was at first reassured that of course she did make a decision. (You might use this point as an opportunity to elaborate on the notion that "choice" is really "choice behavior" that is learned just like other behaviors.) It was acknowledged that during the process of placing the cup on top of the bottle she had undoubtedly felt in a certain way. The discussion then went on to confirm that behavior analysis is 
interested in all of the things that constitute being a person. The class was asked to make a list of all of the things they considered to be important in producing an overall picture of what it means to be a person in the situation being analyzed. They were told that behavior analysts are willing to leave no stone unturned when it comes to developing an explanation for the behavior of a person. This can be an important part of the exercise, especially if the class already has been exposed to misrepresentations of behavior analysis.

For the purpose of this exercise the class was then asked to imagine the following: they were asked to imagine a person who has a "behavior problem" and who has come to them for "therapy." They were told that this imaginary person's problem could be solved if they were helped to become a person who at some point in time decides to place a plastic cup on top of a bottle (i.e., the very behavior the class was addressing). It was suggested that the overall context in which this behavior would be appropriate for this person would be a classroom situation during a course on learning. It was pointed out that such "therapy" would undoubtedly require the manipulation of a complicated set of contingencies. They were told also that the extent to which the therapy would be successful could then be used to address issues concerned with the explanation of behavior. The students, of course, realized that they had just witnessed one way such therapy could take place.

Another important point that was raised was how behavior analysis incorporates reference to current and historical context in developing an explanation. The shaping game itself and the physical structure of environment had helped to produce the behavior; for example, if there hadn't been a bottle there wouldn't have been a decision to put the cup on top of it; if there hadn't been a history of reinforcement the behavior would not have occurred.

The following point was also important. The student who initially posed the problem was working with the following premise: because she was aware of something happening inside her before she placed the cup on top of the bottle, she felt that this something should be regarded as the cause or source of her behavior. From the perspective of other class members observing her behavior, this something was, however, regarded as part of the total change that occurred. Consequently, it was seen as related to the behavior of putting the cup on the bottle but not the cause of it. By classifying this something as "private behavior," the students were given an opportunity to ask new empirical questions. For example, they wondered in what way contingencies could be manipulated to explore the nature of private behavior-public behavior relations (cf. Hayes \& Brownstein, 1986; Keenan, 1997a, 1997b).

For the student who posed the problem discussed here in the first place, the above analysis appeared very strange. In effect, it said to her: The explanation that you provided for your own behavior is mistaken? Indeed, you were looking in the wrong place for the explanation. What is going on inside someone cannot be used as an explanation for his or her behavior. The reason for this is simple. What is going on inside someone at any point in time is in itself part of the total change in his or her behavior that needs explaining. 


\section{KEENAN \& DiLLENBURGER}

To help cement this way of analyzing behavior, a simple scenario was suggested to the class. Instead of looking inside a person for explanations, they were asked to role-play the perspective of an observer; Skinner (1974) referred to this as "adopting the perspective of the other one." For the sake of the exercise the observer was given the name Pat. Thus Pat, who cannot see inside another person's head, can, however, see the environmental antecedents and consequences of this person's behavior. When Pat focuses on the contingencies between these environmental stimuli and the behavior, she can detect lawful relations. That is, if Pat was to systematically manipulate the antecedents and consequences of the behavior in question, she would discover laws that determine the corresponding changes in behavior. These observations are used to build a scientific body of behavioral facts. These are the facts that behavior analysts refer to when they offer an explanation for a particular behavior.

In the class discussion this argument was aided by the consideration of the notion that behavior is a continuous process, from birth through to death. The problem is that this stream of change cannot be stopped for scientific purposes. When scientists speculate about internal mental events determining behavior, they are often able to give the impression that they are able to stop this stream so that such an entity can be isolated. However, closer inspection reveals that an illusion has been spun and that the source of this illusion is in their use of language (Chiesa, 1994). By way of example, the class was asked to suppose that they were observing a person who was engaged in activities that they might describe as "aggressive." The class was told that behavior analysts who might study this behavior would concentrate on the network of contingencies that operate to control it. They would try to identify the environmental antecedents and consequences (both social and physical, current and historical) that maintain this pattern of behavior. The methods used to identify these controlling contingencies would offer insights into how they could be changed so that the behavior also could be changed.

Many students expressed the opinion that since there was no reference to anything mental in such a behavioral analysis, this approach is dehumanizing and at best superficial. For example, they argued that aggressive behavior reflects the operation of aspects of an aggressive personality type. A closer look at this seemingly useful analysis ensued. The main point of discussion was this: what started out as a label for a certain type of behavior (i.e., aggressive) was somehow transformed into an explanation for the same behavior (see Keenan \& Dillenburger, 2000 for examples of how animated cartoons can be used to teach about category mistakes and mentalism).

The students were guided through the following analysis step by step. Firstly, a pattern of behavior is observed. The label AGGRESSIVE is then given. In other words, it is agreed that every time this behavior occurs, the appropriate descriptive word is AGGRESSIVE. At this point, an explanation is not offered. However, when searching for an explanation a common mistake is made. In answer to the question "Why is this person behaving in this way?" the descriptive label is taken and used as an explanation. In doing so the argument becomes circular: 
Q. "Why is this person behaving aggressively?"

A. "Because she/he has an aggressive personality!"

Q. "How do you know that she/he has an aggressive personality?"

A. "Because she/he is behaving aggressively!"

For the purpose of the exercise this question and answer sequence was reworkedpreventing the word "aggressive" from being used inappropriately. Since it simply refers to a particular pattern of behavior the word was deleted from the exchange:

Q. "Why is this person behaving in this way?"

A. "Because she/he has a personality!"

Q. "How do you know that she/he has a personality?"

A. "Because she/he is behaving in this way!"

Things were starting to look a bit odd to the students. They were guided, then, even deeper into the analysis. It was pointed out that the source of the various personality labels were observations of patterns of behavior. Thus, the term "personality" is a descriptive label for particular patterns of behavior. This fact is usually forgotten and a descriptive label ends up as an explanation. The word "personality" was therefore deleted from the exchange in a similar manner as the word "aggressive" previously. This time it was replaced with the term "a pattern of behavior."

Q. "Why is this person behaving in this way?"

A. "Because she/he is engaged in a pattern of behavior."

Q. "How do you know that she/he is engaged in pattern of behavior?"

A. "Because she/he is behaving in this way!"

The analysis described above can be performed with any word that refers to a mental entity as the cause of behavior. Once the mentalistic trappings of a traditional analysis are exposed, it can be seen that we are no closer to finding an explanation for behavior. Students were informed that this is a serious matter because people who think mentalistically, be they politicians, teachers, parents, academic administrators etc., occupy positions of power that determine many aspects of our lives. Our lives are controlled by these people who have not been trained to consider the psychological impact of the contingencies over which they have jurisdiction.

\section{Conclusion}

If handled with care, the shaping game can provide an opportunity for discussing ways in which we can increase self-awareness. To put it simply, information concerning the operation of contingencies can be collated by someone who is observing an individual. This information can then be given to that individual with the result that they are more aware of the factors that control them. At this point the individual can, if she/he so desires, take steps to change the contingencies that are in operation. In so far as this exercise directly addresses issues concerned with the role of private events in the explanation of behavior, the teacher who uses it may find that students will be more discerning of misrepresentation of behavior analysis in their course of study. Not only that, but 


\section{KEENAN \& DiLLENBURGER}

students may find it easier to appreciate the subtlety involved in producing behavior using the social skills involved in shaping (cf. Dahlquist, 1990; Epstein, Repp, \& Cullinan, 1978; Scott, Peters, Gillespie, Blanchard, Edmunson, \& Young, 1973)

\section{The Behavioral Stream}

The inspiration for this gambit occurred a few years ago after an incident occurred on television. The singer Sinead O'Connor tore up a picture of the Pope on a chat show. In doing so she sent a wave of anger throughout the predominantly Catholic S. Ireland. This behavior was so strong (i.e., the reaction to what Sinead did) that we felt justified in trying out a similar procedure in class. In effect, we reworked the demonstration of discriminative control provided by Sinead O'Connor to highlight the principles involved in producing this symbolic control over behavior. The objectives of this exercise are to introduce the idea of the behavioral stream and to provide a forum for examining how the contingencies controlled by different educational systems in a community contribute to conflict between people in that community.

The exercise is in three parts. In the first part you read some quotations to your class to set the scene for explaining the notion of the behavioral stream. This text is accompanied by five figures 1 that graphically elaborate on basic arguments germane to the behavioral stream. In the second part of the exercise you ask volunteers to come forward to help recreate the behavioral stream in front of the class. In the third part this new image is used as a backdrop for exploring some issues concerned with the development of conflict.

\section{Part 1}

At the start of the exercise read to the class the following:

My emergence as a unique individual with my own identity began in the ovaries and testes of my parents when they themselves were embryos in the grandparental womb. The events occurring then were in themselves linked via a continuous thread back through successive ancestral germ lines to the emergence of humanity itself. Just as anthropologists cannot define an exact and absolute point during evolutionary time when our ancient ancestors became human, so I cannot define any single developmental transition at which I became an individual with a clear identity. The evolution of humans and the development of my identity are both continuous processes. (Johnston, 1989, p. 41)

Surprising parallels can be drawn between the notion of an organism as a stream and phenomena which arise in the study of water. For example, continual

\footnotetext{
1 These figures are taken from Keenan \& Dillenburger (2000). Behaviour analysis: A primer. Multimedia CD-ROM. A Celtic Fringe Production, N. Ireland. You can view screenshots of the tutorial at this address: http://psych1.shsc.ulst.ac.uk/behav/index.html.
} 


\section{IMAGES}

movement can give rise to a form which appears static: “. . . when a wave appears behind a stone in a stream, a form is all the time being created out of movement, with new substance constantly flowing through it. This is an archetypal principal of all living creation-an organic form, in spite of continuous chemical change, remains intact." (Schwenk, 1990, p. 33)

Each of these quotations recognizes life to be a continuous process. The study of learning is the study of the ways in which behavior, also a continuous process, changes across time:

Behavior is a difficult subject matter, not because it is inaccessible, but because it is extremely complex. Since it is a process, rather than a thing, it cannot be held still for observation. It is changing, fluid, evanescent, and for this reason it makes great technical demands upon the ingenuity and energy of the scientist. But there is nothing essentially insoluble about the problems which arise from this fact." (Skinner, 1953, p. 15)

Skinner is saying here that a behavioral science should develop techniques for observing and recording the changes that make up the behavioral stream. This notion of a behavioral stream is very useful. A stream is always contained within a particular environment and its course is directed by (i.e., is a function of) the consequences of the interaction between the water and the structure of that environment. The same applies to behavior. One cannot look at behavior without at the same time seeing the circumstances under which it is occurring.

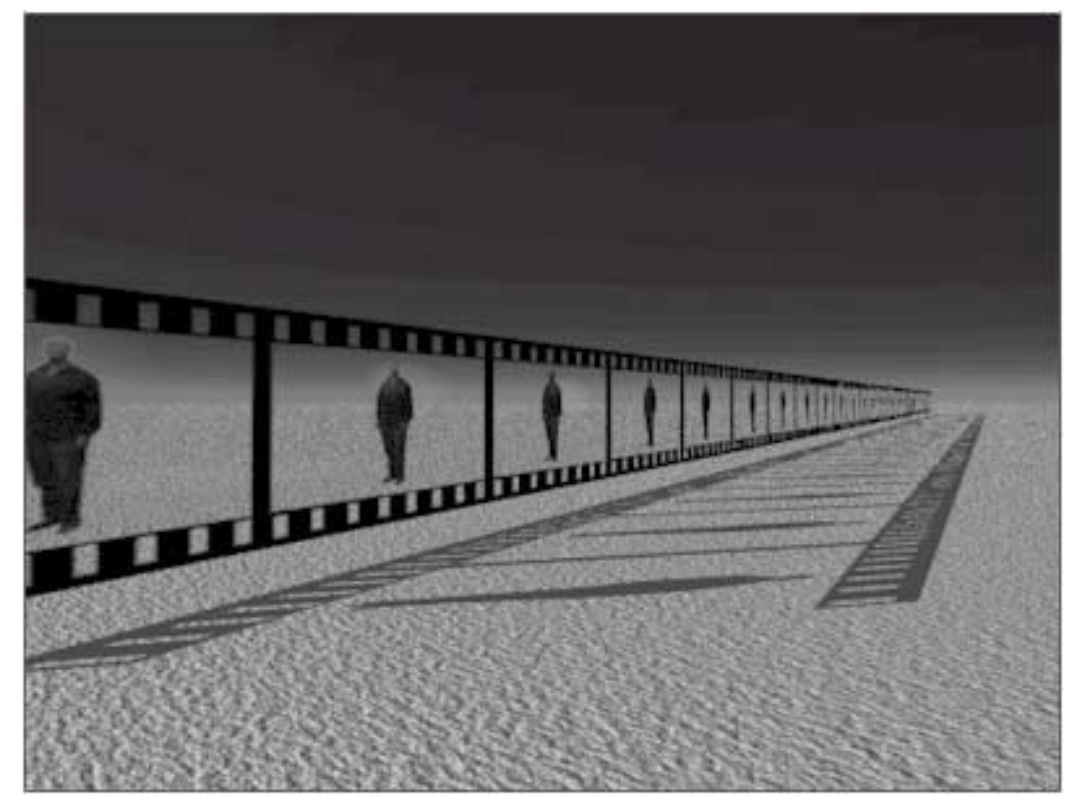

Figure 1. This figure shows the life of an individual to be a continuous process. 


\section{KEENAN \& DiLLENBURGER}



Figure 2. Upon first meeting a person we observe only a snapshot in their life.

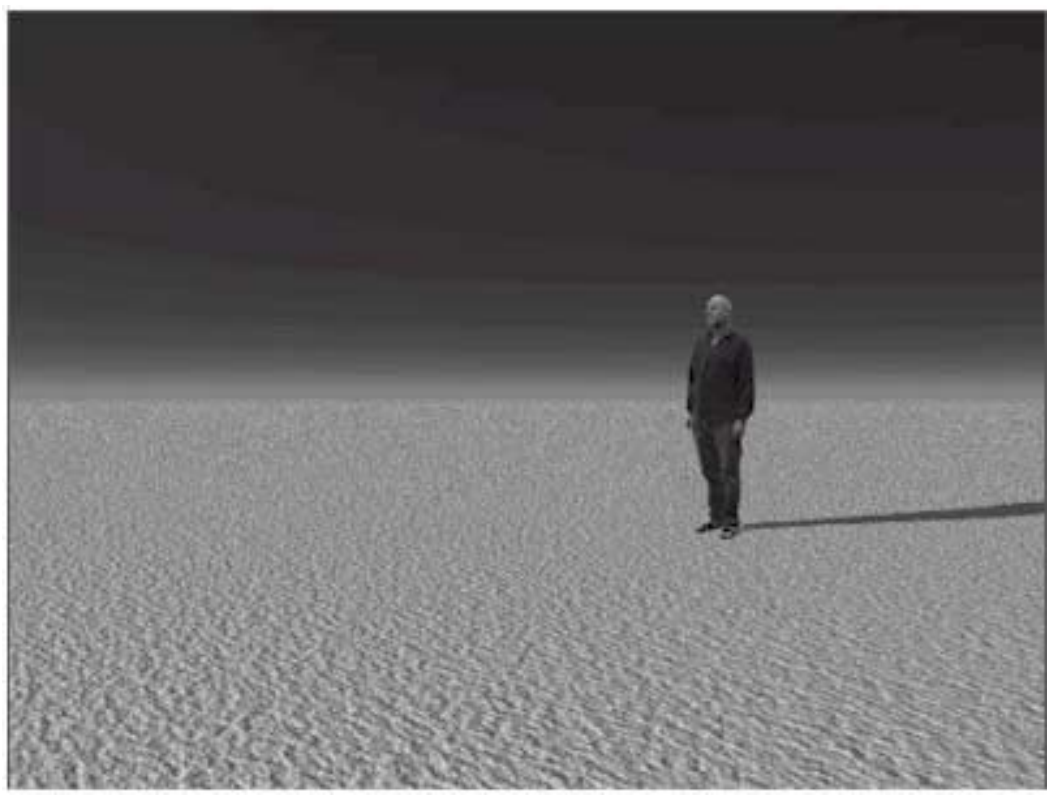

Figure 3 . The image of a person as a continuous process is difficult to retain. 


\section{IMAGES}



Figure 4. A consequence of this is that we usually engage in a mentalistic analysis when we attempt to explain a person's behavior. That is, explanations are formulated in such a way that they refer to events taking place inside, in the person's brain or in their mind.

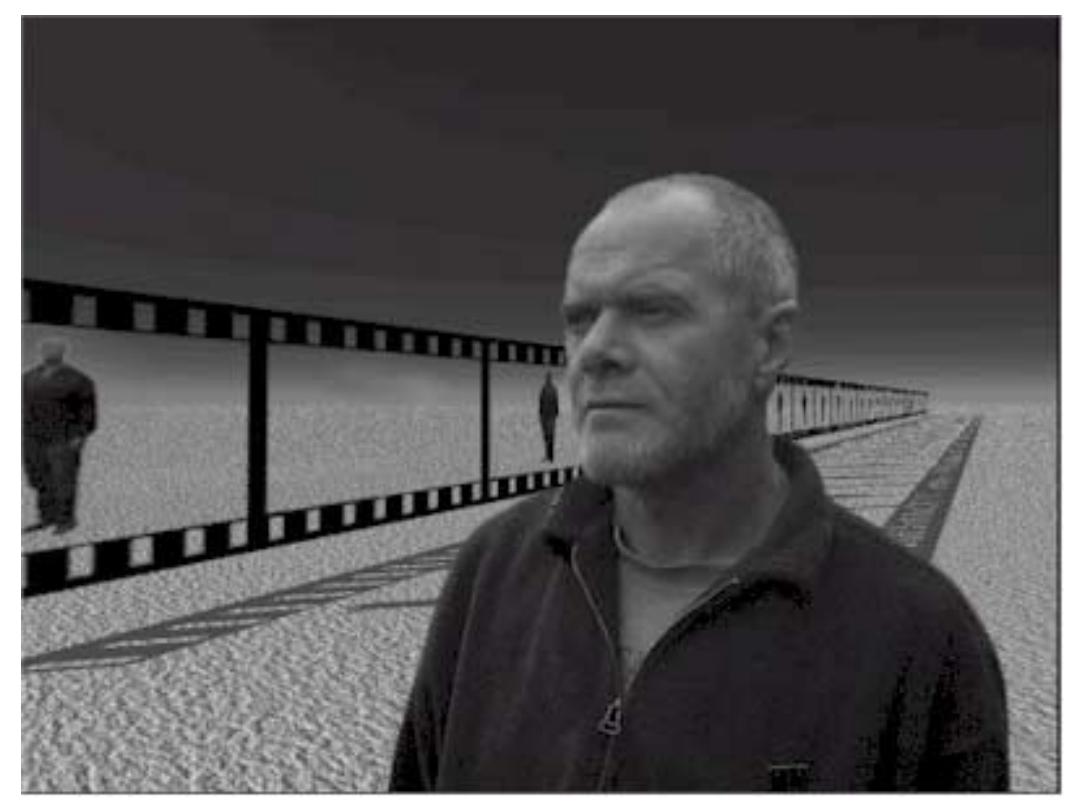

Figure 5. A natural science perspective, however, enables us to retain the image of a continuous process. From this perspective, the purpose of scientific enquiry is to relate segments of this continuous process to the independent variables of which they are a function. So-called mental events are part of this process, not the explanation for what is observed. 


\section{KEENAN \& DILLENBURGER}

Part 2

Now we turn to some "performance art" to help portray the ideas expressed above. That is, with the help of a couple of students your objective is to create a 3dimensional model that portrays the behavioral stream.

\section{Materials}

You will need the following: 2 baby dolls; some wool; hair clips; sticky tape; 2 sheets of blank paper; 4 sheets of paper, one with a picture of a man, one with a picture of a woman, one with a picture of the Queen of England, one with a picture of the Pope; a large piece of card (about 3 square $\mathrm{ft}$ ) that is black on one side and white on the other side; if possible, a short video clip of a human egg at the moment of fertilization.

\section{Procedure}

Ask for two volunteers to come forward. Have them stand facing each other at about $3 \mathrm{ft}$ apart. Behind each of them place a doll on the floor (see Figure 6).

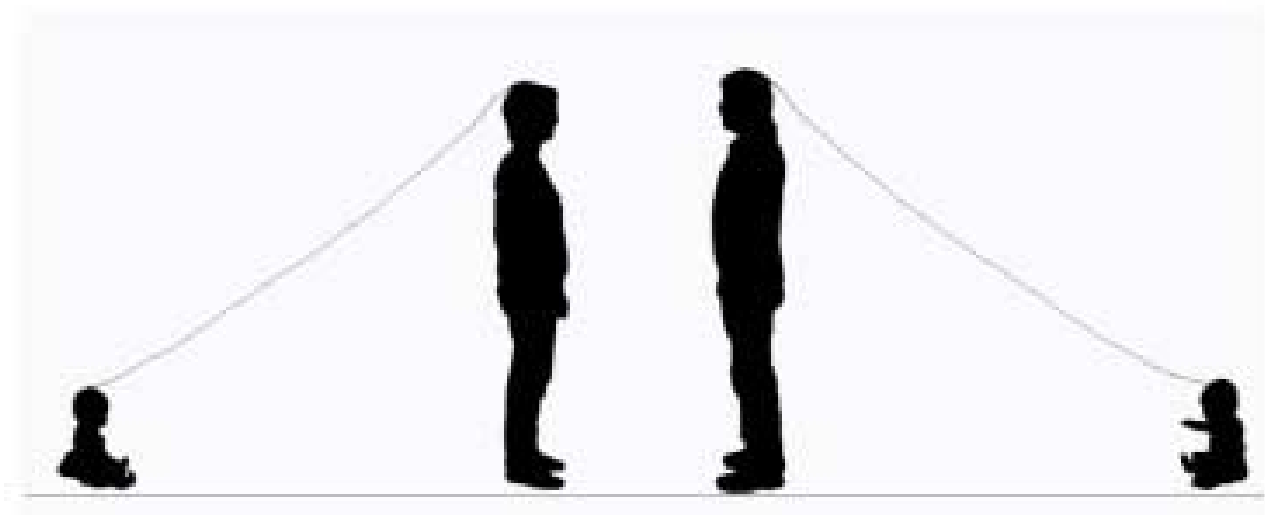

Figure 6. By bringing students to the front of the class and using the props described in the text, you can add another dimension to the explication of the behavioral stream.

Ask two other students to attach a piece of wool from the top of the head of each doll to the head of the person in front of it. You should now have each volunteer connected to a doll. Hey presto! Here is visual representation of the behavioral

\footnotetext{
${ }^{2}$ The Queen of England and the Pope are used in this procedure because they represent polar opposites of the divided community of N. Ireland; Protestants profess allegiance to the Queen while many Catholics profess allegiance to the Pope. It is not uncommon in either community to see graffiti, which says "F - the Pope" or "F- the Queen." In your selection of stimuli, choose pictures from two sets of groups, either religious or political, that represent the figure heads of conflicting views.
} 


\section{IMAGES}

stream! (If you have a video clip of a human egg being fertilized, you can place it behind one of the dolls to complete the picture.)

\section{Part 3}

This image provides a platform for raising questions concerned with the explanation of behavior. Point out to the class that every observation is a snapshot in time, and an end product of all of the experiences that happened to a person up to that point in time (use Figures 1-5 in conjunction with your new 3-D image to help portray the argument). Inform the class that the word "experience" originally meant "something a person had gone through" (Skinner, 1989). This "thing that they have gone through" is an interaction with their physical and social environment. Work through the following statements that include (rhetorical) questions (Q.) and answers (A.):

David Suzuki, Professor of Genetics at the University of British Columbia clarified the role of genetics on behaviour when he said that: "Human behavior takes place in a cultural context. The way genes affect us depends on our circumstances. So if you read in the newspapers that scientists have discovered a gene for alcoholism, criminality, or intelligence, or whatever, take it with a pinch of salt. To tell how a particular gene affects someone the scientist would need to know everything about that person's environment as well, and even that might not be enough." (Suzuki, 1993)

When a child comes into the world, his/her social environment is already organized. It follows from this that many wide-ranging questions are relatively easy to address. For example, we could ask the following:

Q. Is it possible to train a child to be a Catholic, or a Protestant, or a Serb, or a Croat, or a Hindu, or a Muslim, etc.?

A. Of course it is, because it happens all over the world.

You can also address questions like these:

Q. Is it possible to train a child in such a way that she/he is later able to feel justified in killing another human being?

A. Again the answer is "Yes!"; armies are doing it all over the world!

Q. Is it possible to train a person to rationalize their habit of collecting pieces of paper and bits of metal?

A. This refers to money!

Q. Is it possible to train a person in such a way that she/he is left with the feeling of being loved, of being depressed, of being frustrated, ... ? 


\section{KEENAN \& DiLLENBURGER}

Notice how the word "train" seems to cause problems in this question. It somehow seems very shallow and dehumanizing. That reminds me of another question:

Q. Is it possible to arrange circumstances in such a way that a person views the word "train," when applied to people, as very shallow and dehumanizing?

I think most people here would have no problems with this statement. However, there is a more general view of the word "train" that does not cause these problems; it is one adopted by behavior analysts. From this view the word "train" is simply a term that refers to the procedures employed in education generally to bring about particular kinds of behavior.

This way of asking rhetorical questions in class can be very effective, so be sure to move slowly and give students time to reflect.

Walk along the line connecting each volunteer to a doll and tell the class that this area represents all of their previous interactions with the environment (i.e., their "training"), culminating in the final observation. Say the following:

Here we see two individuals facing each other. Behind them we see them as they were just after birth. Many changes have taken place between these two points of time, changes that have resulted in the babies growing, through childhood and adolescence, becoming the adults we see in front of us now. They have grown physically, due to the nourishment they have received, and they have also developed as individuals as a result of their experiences in their journey through life. Let's imagine that we can take this stream of experience and compress it, compress it into this strand of wool. The wool contains everything that has happened to these individuals, and everything they have ever done, resulting in the two people that we see in front of us. Of course, the story doesn't really start at the moment of their birth. We could extend the wool further back, beyond the baby, through the point of its conception, through its parents' births, back through the evolution of the species until we reach the first living cell of life on earth.

Now let's pretend that the person on the left is a Catholic and that the person on the right is a Protestant.

Get the class to work in small groups and have them come up with some examples of the contingencies that children are exposed to when they are being trained in either religion. What actually happens to them? What do they have to do, and what are the consequences of behaving or not behaving in accordance with the rules prescribed by each religious culture?

Discuss the contingencies identified by each group and use your visual stimuli to remind the students that these contingencies were contained in the area bound by each piece of wool. Finish with the conclusion that the explanation for any behavior at the final moment of observation is not to be found by looking inside the person. Show them (you can now physically do this by pointing to the wool!) 


\section{IMAGES}

that the explanation for behavior is to be found in the contingencies operating in the subject's current and historical context.

At this point you will need to focus on a specific behavior to back up your argument. This is where the pictures come in. Inform the class (who, by the way, have not yet seen the pictures!) that a simple way to explore the effects of conditioning is to present certain stimuli to your subjects and to monitor the responses produced. Stand between the volunteers and say the following to the class:

For a few minutes now I want to concentrate on these two organisms.

Now talk to the volunteers:

I don't know what religion you are, but I want you to imagine that you are a Catholic, and I want you to imagine that you are a Protestant. Soon you will experience something, and I want you to react as you imagine you might in the religious roles that have been assigned to you. Your reaction doesn't even have to involve any movement, a feeling will do.

Now do the following:

1. Pick up a blank piece of paper and show it first to the class and then to each of the volunteers. Tear it in half. Expect a bemused reaction from the volunteers and from the class in general.

2. Pick up a picture of a man and show it first to the class and then to each of the volunteers. Tear it up. Expect a bemused reaction from the volunteers and from the class in general.

3. Pick up a picture of a woman and show it first to the class and then to each of the volunteers. Tear it up. Expect a bemused reaction from the volunteers and from the class in general.

4. Pick up a picture of the Queen and show it first to the class and then to each of the volunteers. Ask for permission to tear it up. Expect a much stronger reaction. Remember this reaction because it provides important data for improvised discussions afterwards.

5. Pick up a picture of the Pope and show it first to the class and then to each of the volunteers. Ask for permission to tear it up. Expect a chortle from the group of students. You will also notice talking and sniggering between students as they catch on to what you are doing. Say the following:

We just saw two individuals reacting to stimuli in a certain way. The stimuli were the same for both of them but they responded differently. Why should that be? Let's look at it like this. We'll go back to the point at which these individuals were born (point to dolls). Imagine that these two babies were born with fully developed perceptual, reasoning and verbal faculties. How do you think they would have reacted to the pictures being torn? I think you would agree that they wouldn't have been outraged at all. But why not? Is this baby and this adult one and the same person? The answer is to be found in the wool, 


\section{KEENAN \& DiLLENBURGER}

in the stream of events that constitute their own unique experiences, their interactions with the world. Their respective responses are an indication of the way(s) in which they were trained.

To conclude this session I would like to introduce another image to illustrate the implications of this point.

Ask the two volunteers to close their eyes. Take the black and white card and hold it between them so that they cannot see each other. Tell the class that you requested their eyes to be closed as a way of representing the original innocence of each child. Say to the volunteers:

You may open your eyes. What you see is a representation of your view of truth. That is, having traveled along different paths in life you each are in a position to defend what you consider to be the "truth" about your relation to your God.

Ask each volunteer the following question:

What color is truth?

\section{Conclusion}

As a working metaphor for different worldviews, this exercise is filled with opportunities for a broad range of discussion topics. Whatever the questions raised by the students you will be able to refer to the model in front of them in your answers. When points of conflict or confusion arise in discussion you can address them by referring to the appropriate part of the model. The advantage of this is obvious. The discriminative control afforded by the visual props provides a common medium for communication. This is more difficult to do with the written word alone.

\section{General Discussion}

Generally speaking, the landscape of behavior analysis is bereft of scientific images intended to capture the imagination of students. This is not to say that graphical representations of functional relations cannot be aesthetically pleasing to the seasoned observer. However, since communication is an important social aspect of our discipline, it needs to be recognized that the printed word is only one of many possible interfaces between students and the world of behavior analysis. In this paper we have shown what can be done when more effort is directed at experimenting with a variety of media. Our experience with these two exercises has shown us that they can leave lasting impressions. For example, for successive years students who choose to study behavior analysis with the first author as an optional module in their final year of a general undergraduate degree in social psychology repeatedly recount the behavioral stream exercise in their first year of studies as one that changed their views on how to look at the conflict in N. Ireland. Hopefully these exercises will help to inspire others to experiment with their 


\section{IMAGES}

teaching materials in a way that transcends the current appreciation of the rich heritage of the scientific image. In closing we leave the reader with the words of a scholar who dedicated himself to elucidating the role that the scientific image has played in the advancement of science generally.

The scientific mind may be characterized as the bearer of two torches: one of insatiable curiosity and the other of a will to impart understanding. Nevertheless, scientific studies are usually published in a language seemingly impenetrable by the nonscientist. Images-even complex ones-can, however, impart the scientist's objectives in startlingly direct ways. . . Images trigger an internal motion: the deliberate perusal of the elements in a picture. By seeing into the picture, the viewer transforms the static image into an active intellectual experience. In some instances such scrutiny may generate an aesthetic response, or at least pleasure in the curiosity and ingenuity displayed by the scientist/illustrator....

Understanding the content of a scientific illustration requires some description of the phenomenon to be studied, as well as an understanding of its labels and terms. Unlocking meaning can bring about the exhilaration of a shared intellectual passion, a passion that has animated the scientific community throughout the history of mankind. (Robin, 1992, p. 9)

\section{REFERENCES}

Bailey, M., \& Bailey, R. E. (1993). How to train a trainer. Proceedings of the Association for Behavior Analysis. Kalamazoo, MI.

Catania, A. C. (1991). The gifts of culture and of eloquence? An open letter to Michael J. Mahoney in reply to his article, "Scientific psychology and radical behaviorism." The Behavior Analyst, 14, 61-72.

Catania, A. C. (1997). Learning (4th ed.). Englewood Cliffs: Prentice Hall.

Chiesa, M. (1994). Radical behaviorism: The philosophy and the science. Boston: Authors Cooperative, Inc. Publishers.

Dahlquist, L. M. (1990). The treatment of persistent vomiting through shaping and contingency management. Journal of Behavior Therapy and Experimental Psychiatry, 21, 77-80. http://dx.doi.org/10.1016/0005-7916(90)90052-M

Epstein, M. H., Repp, A. C., \& Cullinan, D. (1978). Decreasing "obscene" language of behaviorally disordered children through the use of a DRL schedule. Psychology in the Schools, 15, 419-423. http://dx.doi.org/10.1002/1520-6807(197807)15:3<419::AID-PITS2310150321>3.0.CO;2-K

Fraley, L. E. (1997). An academic home for a natural science. Behavior and Social Issues, 7, 89-93. http://dx.doi.org/10.5210/bsi.v7i2.305

Grote, I. (1997). Natural science has a home. Behavior and Social Issues, 7, 94-98. http://dx.doi.org/10.5210/bsi.v7i2.306

Hayes, S. C., \& Brownstein, A. J. (1986). Mentalism, behavior-behavior relations and a behavior-analytic view of the purposes of science. The Behavior Analyst, 9, 174-190.

Johnston, J. M. (1997). The place of behavior analysis in the academy. Behavior and Social Issues, 7, 99-101. http://dx.doi.org/10.5210/bsi.v7i2.307

Johnston, M. (1989, December 9). Did I begin? New Scientist, 36-42.

Keenan, M. (1997a). Teaching about private events in the classroom. Behavior and Social Issues, 6, 75-84. 


\section{KEENAN \& DiLLENBURGER}

Keenan, M. (1997b). 'W-ing': teaching exercises for radical behaviourists. In K. Dillenburger, M. F. O'Reilly, \& M. Keenan (Eds.), Advances in behaviour analysis. Dublin: UCD Press.

Keenan, M. (1998, April). Is it time for behavior analysts to use multimedia? Invited address at the meeting of The Experimental Analysis of Behavior Group, London, England.

Keenan, M., \& Dillenburger, K. (2000). Behaviour analysis: A primer. [CD-ROM]. N. Ireland: A Celtic Fringe Production.

Lee, V. L. (1989). Comments about the isolation of behavior analysis. The Behavior Analyst, 12, 85-87.

Leslie, J. C. (1996). Principles of behavioral analysis. Amsterdam: Harwood Academic Publishers GmbH.

Lonigan, C. J. (1990). Which behaviorism? A Reply to Mahoney. American Psychologist, 45, 1179-1181. http://dx.doi.org/10.1037/0003-066X.45.10.1179

Miltenberger, R. (1997). Behavior modification: Principles and procedures. Pacific Grove: Brooks/Cole Publishing Company.

Morgan, W. G. (1974). The shaping game: A teaching technique. Behavior Therapy, 5, 271-272. http://dx.doi.org/10.1016/S0005-7894(74)80144-9

Morris, E. K. (1985). Public information, dissemination, and behavior analysis. The Behavior Analyst, 8, 95-110.

Morris, E. K. (1990). What Mahoney “knows.” American Psychologist, 45, 1178-1179. http://dx.doi.org/10.1037/0003-066X.45.10.1178

Morris, E. K. (1992). The aim, progress, and evolution of behavior analysis. The Behavior Analyst, 15, 3-29.

Pryor, K. (1985). Don't shoot the dog. New York: Bantem.

Rakos, R. (1997). Moving to a new home: Will anyone live there and who will know the address? Behavior and Social Issues, 7, 102-106. http://dx.doi.org/10.5210/bsi.v7i2.308

Robin, H. (1992). The scientific image: From cave to computer. NewYork: Harry N. Abrams, Inc.

Schwenk, T. (1990). Sensitive chaos. London: Rudolf Steiner.

Scott, R. W., Peters, R. D., Gillespie, W. J., Blanchard, E. G., Edmunson, E. D., \& Young, L. D. (1973). The use of shaping and reinforcement in the operant acceleration and deceleration of heart rate. Behavior Research and Therapy, 11, 179-185. http://dx.doi.org/10.1016/S0005-7967(73)80004-X

Skinner, B. F. (1953). Science and human behavior. New York: Free Press.

Skinner, B. F. (1974). About behaviorism. New York: Knopf.

Skinner, B. F. (1989). Recent issues in the analysis of behavior. Ohio: Merrill.

Suzuki, D. (1993). Cracking the code. British Broadcasting Co-operation.

Wulfert, E. (1997). The exodus of behavior analysis: Is "splendid isolation" the way to go? Behavior and Social Issues, 7, 107-112. http://dx.doi.org/10.5210/bsi.v7i2.309

Wyatt, W. J. (1990). Radical behaviorism misrepresented? A reply to Mahoney. American Psychologist, 45, 1181-1183. http://dx.doi.org/10.1037/0003-066X.45.10.1181 